\title{
Terrasses de culture et jessours du Maghreb oriental
}

In: Méditerranée, Tome 71, 3-4-1990. L'agriculture en terrasses sur les versants méditerranéens; histoire, conséquences sur l'évolution du milieu. Séminaire - Aix-en-Provence - 3 février 1990. pp. 51-53.

\begin{abstract}
The island of Delos preserves ancient terraces which can be dated by both epigraphy and excavations of theV'c. B.C., at the latest. The important -work performed for the construction of the terraces proves the prominent part played by agriculture in the ancient city.

Résumé

L'analyse du détritisme alluvial holocène du bassin-versant du Vallat de Monsieur-Vallat Neuf (Basse- Provence) éclaire l'évolution de la dynamique érosive historique, dans le contexte d'une économie agricole traditionnelle caractérisée par l'aménagement de terrasses de culture et le contrôle des écoulements. L'étude met en évidence les conséquences morphodynamiques majeures des périodes d'extension ou de rétraction de l'espace agricole.
\end{abstract}

Citer ce document / Cite this document :

Ballais Jean-Louis. Terrasses de culture et jessours du Maghreb oriental. In: Méditerranée, Tome 71, 3-4-1990. L'agriculture en terrasses sur les versants méditerranéens; histoire, conséquences sur l'évolution du milieu. Séminaire - Aix-en-Provence - 3 février 1990. pp. 51-53.

doi : 10.3406/medit.1990.2684

http://www.persee.fr/web/revues/home/prescript/article/medit_0025-8296_1990_num_71_3_2684 


\section{Terrasses de culture et jessours du Maghreb oriental.}

\section{Jean-Louis BALLAIS*}

Cette brève présentation de quelques exemples de systèmes de structuration de l'espace agricole au Maghreb oriental a pour but principal de faire une sorte de contrepoint aux exemples pris au nord de la Méditerranée. Elle envisagera surtout les problèmes d'évolution, de dégradation et de destruction des structures construites en s'appuyant, pour l'essentiel, sur des observations de terrain.

\section{1 - LES TERRASSES DE CULTURE}

L'accumulation, naturelle ou artificielle, de dépôts à l'amont des terrasses de culture peut être un sujet de controverse. Dans les étages les plus humides du climat méditerranéen (jusqu'au semi-aride inclus), la solifluxion peut jouer un rôle considérable, sur substratum argileux ou marneux. C'est le cas, par exemple, à Aïn Zouza (fig.1), site antique de Tunisie centrale. Là, la solifluxion laminaire généralisée est omniprésente, depuis au moins l'époque romaine, sur un bas plateau en pente douce. Chaque alignement de pierres (limite de parcelle culturale actuelle, enceintes antiques, cimetière mégalithique pré-romain) provoque à son amont une accumulation qui domine l'aval de plusieurs décimètres. Au centre du site, l'accumulation atteint $4,46 \mathrm{~m}$ dont $1,86 \mathrm{~m}$ avant la construction du fort byzantin et $2,60 \mathrm{~m}$ depuis. Il est vrai que plusieurs circonstances sont particulièrement favorables: léger pendage du substratum calcaire en sens inverse qui facilite la stagnation de l'eau, neige hivernale, défrichement total de la forêt de Pinus halepensis remplacée par des labours.

La destruction des terrasses de culture, par contre, ne fait que commencer au Maghreb oriental. Dans l'étage aride des Aurès (Algérie), par exemple à Nara, c'est le ruissellement concentré et diffus qui crève les terrasses abandonnées les premières, celles qui protégeaient les cultures sèches, sur les plus fortes pentes. Mais la recolonisation par la végétation spontanée des terrasses anciennement irriguées peut être assez rapide, comme à Iguelfène, pour que les terrasses se maintiennent. Enfin, dans le cas des terroirs totalement et définitivement évacués pendant la guerre de Libération et qui occupaient de vieilles coulées boueuses (Sanef, Kebach), l'érosion linéaire reste marginale, les terrasses disparaissent surtout par éboulement (BALLAIS, 1989).

Ces quelques observations confirment qu'il n'y a pas de relation univoque entre l'abandon des terrasses de culture et une reprise vigoureuse de la morphogénèse. Outre l'étage climatique, interviennent les formes (en particulier par l'intermédiaire des pentes), les formations superficielles, les pratiques culturales (irrigation ou cultures sèches) et les modalités (surface intéressée, vitesse) de l'abandon des cultures.

Comme souvent, l'âge des terrasses reste difficile à préciser, malgré la logique de la position ancienne de J. DESPOIS (1956) les reliant à la vieille civilisation agraire berbère des montagnes. Aux environs de Kasserine, certaines terrasses dateraient de l'époque romaine (HITCHNER, sous presse). Mais les seules qui soient incontestablement anciennes sont celles du djebel Ousselet, à l'ouest de Kairouan (fig. 1), évacué de force au milieu du XVIII ${ }^{\circ}$ siècle. Très bien adaptées au modelé de détail, elles s'articulent avec un système de barrages et de réservoirs de haute époque islamique (SOLIGNAC, 1952).

* UFR des Sciences géographiques et de l'aménagement, Université d'Aix-Marseille 


\section{2 - LES JESSOURS DU SUD TUNISIEN.}

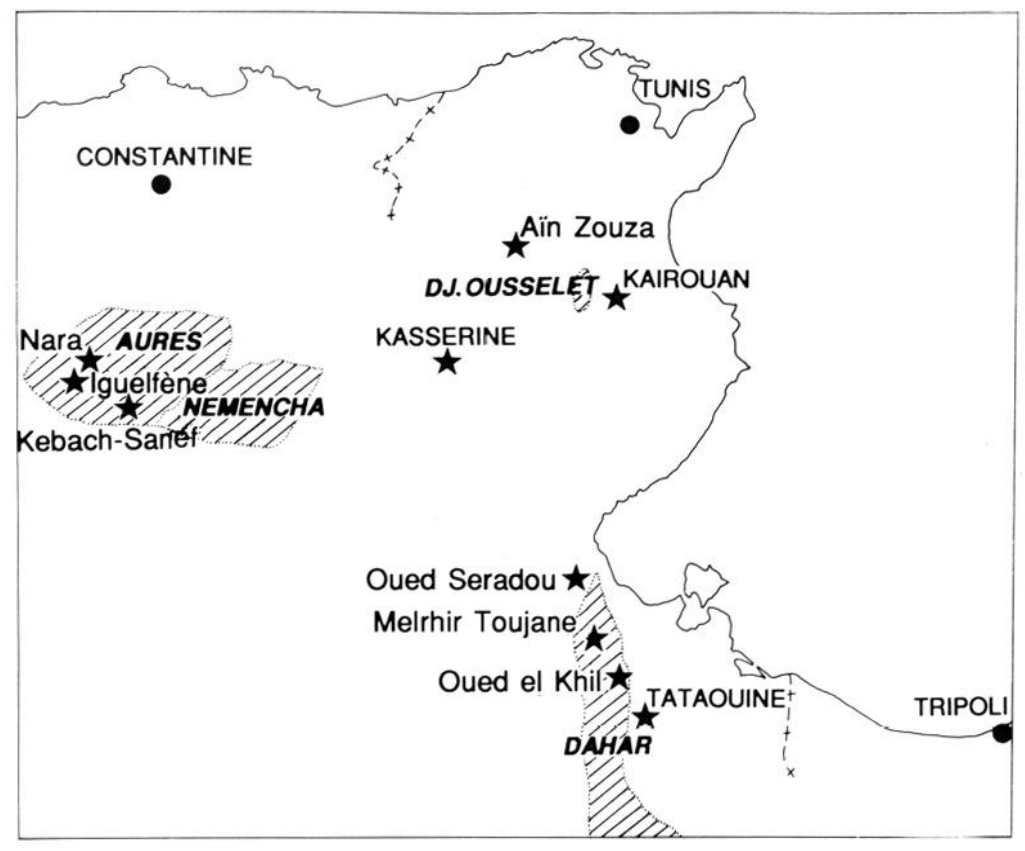

Fig. 1 - CARTE DE LOCALISATION
Les jessours ne sont pas :

- de simples barrages pour retenir l'eau (à la différence des barrages romains des $\mathrm{Ne}$ mencha ou islamiques du Kairouanais),

- des tabia, longs talus de terre barrant les interfluves surbaissés des piémontset d'extension très rapide deuis une vingtaine d'années, comme vers Tataouine (ABICHOU, 1987),

- de simples terrasses de culture car ils n'arment pas les versants.

Ce sont des barrages constitués d'une digue de terre ou de pierres sèches bien appareillées, longue de quelques mètres à quelques dizaines de mètres, qui barre totalement un talweg sauf sur un des bords où un déversoir de pierre (souvent cimenté) est aménagé. Le but recher-

ché est l'accumulation, lors d'une crue, à la fois des alluvions et de l'eau. Il s'agit de créer un terroir, et un terroir irrigué. Cela suppose une fourniture abondante d'alluvions fines ce qui limite très étroitement cette technique à la zone d'affleurement des sables limoneux éoliens du Dahar. A la limite de l'étage saharien, localement et parfois, le vent peut participer à cette accumulation à l'amont du jessour. Traditionnellement édifiés à la main, les jessours le sont maintenant au boutoir à lame. L'équipement, à sa perfection, atteint tous les petits talwegs de versant (Melrhir Toujane) et tronçonne totalement l'oued axial (oued el Khil) (fig. 1).

Le terroir créé derrière chaque jessour atteint quelques dizaines à quelques centaines de mètres carrés, de quoi planter au moins un arbre fruitier (olivier surtout, mais aussi figuier et palmier) et semer de l'orge.

Ces jessours sont évidemment très fragiles, à la merci d'une crue plus forte que les autres, commeen 1979 (BONVALLOT, 1979). Cette sensibilité à l'érosion linéaire est accrue par la mauvaise qualité de certains déversoirs dont la hauteur a été mal appréciée. A l'extrême, le déversoir peut être aussi haut que le jessour. Alors l'accumulation permet au ruisssellement de former un plunge-pool et, par érosion régressive, d'entailler vigoureusement le remplissage lité. En quelques minutes à quelques dizaines de minutes, des tonnes de sables limoneux sont évacués vers l'aval, les racines des arbres mises à nu. Si la crue est durable, tous les jessours d'un oued peuvent être entaillés, de l'aval vers l'amont.

Les jessours sont très étroitement localisés dans l'espace, dans le Dahar où se maintient une vieille société berbère troglodyte. Leur grande ancienneté est maintenant prouvée, suite à des travaux récents (TROUSSET, 1974; BALLAIS, 1990) puisqu'un jessour daté du II ${ }^{e}-\mathrm{III}^{e}$ siècle de notre ère a été identifié sur l'oued Seradou (fig. 1). La coupe de son accumulation d'amont (en cours d'étude) est tout à fait comparable à celle des accumulations des jessours actuels.

Ainsi, au sud de la Méditerranée, les terrasses de culture sont encore très souvent utilisées et entretenues. L'étude précise des processus de leur destruction peut fournir des modèles susceptibles de faire mieux comprendre la morphogénène qui s'est développée, au nord de la Méditerranée, dans les mêmes conditions, il y a quelques dizaines d'années. Par contre, les jessours constituent une forme très originale, parfaitement adaptée aux conditions locales de sociétés traditionnelles plusieurs fois millénaires. Cependant, leur abandon, qui commence parfois, peut aussi fournir un modèle, cette fois en Afrique du Nord, susceptible de faire mieux comprendre la morphogénèse des terrasses alluviales historiques. 


\section{RÉFÉRENCES BIBLIOGRAPHIQUES}

ABICHOU A. (1987). - El Bahira (Sud tunisien). Deux géofaciès dans un milieu aride, Mémoire de Maîtrise, Caen, 113 p., multigr.

BALLAIS J.L. (1989). - Aurès, Encyclopédie Berbère, VII, Edisud, p.1066-1095.

BALLAIS J.L. (1990). - Les terrasses historiques de Tunisie, Z. für Geom., sous presse.

BONVALLOT J. (1979). - Comportement des ouvrages de petite hydraulique dans la région de Médenine (Tunisie du Sud) au cours des pluies exceptionnelles de mars 1979, Cahiers ORSTOM, Ser. Sc. Hum., vol. XVI, $\mathrm{n}^{\circ} 3$, p. 223-249.

DESPOIS J. (1956). - La culture en terrasses en Afrique du Nord, Annales E.S.C., p. $42-50$.

SOLIGNAC M. (1952). - Recherches sur les installations hydrauliques de Kairouan et des steppes tunisiennes du VII au XI' siècle (J.-C.), Annal. Inst. Et. Orient., Alger, t. X, p. 5-273.

TROUSSET P. (1974). - Recherches sur le limes Tripolitanus du Chott el Djerid à la frontiere tuniso-libyenne, Paris, CNRS. 